\title{
Numerical investigation of internal crossflow effects on film cooling performance at turbine blade suction surface
}

\author{
Shuo ZHAO*, Jingzhou ZHANG* and Xiaoming TAN* \\ ${ }^{*}$ College of Energy and Power Engineering, Nanjing University of Aeronautics and Astronautics \\ No. 29, Yudao Street, Nanning, Jiangsu province, 210016, China \\ E-mail: zhangjz@nuaa.edu.cn
}

Received: 26 June 2018; Revised: 17 August 2018; Accepted: 26 September 2018

\begin{abstract}
A series of numerical simulations are performed to study the internal crossflow effect on single-row film cooling performances on a turbine blade suction surface, under the representative film-cooled engine-simulated conditions. The cylindrical and fan-shaped holes are considered, both having the same length-to-diameter of 3 . In the current simulations, the blowing ratio $(B r)$ is selected as 1,2 and 3 respectively. The velocity ratio of the internal crossflow to ejection jet $(V r)$ is selected as 0,1 and 2, respectively. The results show that the helical flow feature is dominant inside film hole with the presence of internal crossflow and the ejection jet is pushed toward one side in accordance to the internal flow direction. For the fan-shaped hole, the effect of internal crossflow on mutual interaction between ejection jet and primary flow downstream the film cooling hole is relatively weaker in compared to the cylindrical hole. In general, the velocity ratio of $V r=1.0$ has a little influence on the film-hole discharge coefficient. However, under a high velocity ratio of $V r=2.0$, approximately $15 \% \sim 20 \%$ reduction of discharge coefficient is produced for the cylindrical hole, and $20 \% \sim 27 \%$ reduction for the fan-shaped hole. In the viewing of laterally-averaged adiabatic film cooling effectiveness, the impact of internal crossflow effect is more profound for the cylindrical hole. In general, a moderate velocity ratio $(V r=1.0)$ plays a positive role on film cooling improvement but a high velocity ratio $(V r=2.0)$ is confirmed to reduce the film cooling effectiveness.
\end{abstract}

Keywords : Film cooling, Blade suction surface, Internal crossflow, Cylindrical hole, Fan-shaped hole

\section{Introduction}

Promoting the turbine inlet temperature level is an inevitable technological routine for improving the thermodynamic performance of turbine engines. In the development of advanced gas turbines, exploring highly-efficient cooling techniques is a key issue to the engineers, in order to meet the demand of keeping the thermal loads on turbine hot section components at an acceptable level (Bunker, 2007). Beside, accurate thermal analysis is also important in the fine design of cooling configuration in the practical applications.

Film cooling is an important scheme in the cooling configurations of turbine hot section components. Over past decades, many efforts had been paid to improve its potential. One of the most inspiring and remarkable achievements in the advanced film cooling technology was the successful use of innovative shaped film cooling holes (Bell et al., 2000; Bunker, 2005).

Fan-shaped hole is commonly regarded as the most typical shaped-hole, which was initially originated at the 1970's (Goldstein et al., 1974). Due to its diffusing exit-shape, anti-kidney vortices effect is produced by the fan-shaped hole, leading to less penetration of the ejection jet and wider film-layer coverage in comparison with the cylindrical film-hole (Haven et al., 1997; Thole et al., 1998; Gritsch et al., 1998 a, b). Although new types of shaped film cooling holes are more attractive to many researchers recently (e.g., Okita and Nishiura for arrowhead-shaped hole, 2007; Heidmann and Ekkad for branch-shaped hole, 2008; Sundaram and Thole for trench-shaped hole, 2009; Dai and Lin for crescent-shaped hole, 2011; Yang and Zhang for ridge-shaped hole, 2012; Kim and Kim for crater-shaped hole, 2016; Ramesh et al. for tripod-shaped hole, 2016; Zhu et al. for converging slot-hole and diffused slot-hole, 2017), the fan-shaped hole is still a concerned issue in the film cooling technique because it is a more realistic 
configuration in the real applications. To our knowledge, two main concerns were emphasized on the fan-shaped hole film cooling more recently. In the view of bringing out the latent potentiality of the existing cooling configuration, multi-parameter optimization of the fan-shaped hole film cooling was an important research concern (Lee and Kim, 2010, 2011; Wang et al., 2016). Another concern was the extensive demonstration of fan-shaped film cooling under more representative application situations. For example, most of the previous researches for fan-shaped film cooling were conduced on the flat-plate models with a simple plenum-fed scheme. However, in the real applications, the film-protected surfaces are often curved and accompanied with the internal crossflow effect. As the surface curvature and coolant-fed mode have evident influences on the mutual interaction between the ejection jet and the mainstream (Leylek and Zerkle, 1994; Kohli and Thole, 1998; Ethridge et al., 2001; Gao et al., 2008, 2009; Qin et al., 2015), the fan-shaped hole film cooling performance is consequently affected by the curvature effect of surfaces and the entrance effect of film cooling holes.

In related to the plenum coolant-fed mode, the film cooling performance could be strongly affected by the internal crossflow effect (Wilfert and Wolff, 2000). Gritsch et al. (2003) and Saumweber and Schulz (2008) investigated experimentally the effect of internal coolant crossflow on film cooling performance of cylindrical and fan-shaped cooling holes. Their results indicated that the internal crossflow effect makes the film cooling effectiveness improved for the cylindrical hole case but reduced for the fan-shaped hole case, when compared to the plenum-fed scheme. Peng and Jiang (2012) investigated the internal crossflow effects on film cooling performances of three types of film cooling holes. The film cooling effectiveness of cylindrical and trenched holes was found to be increased with the presence of internal crossflow. But the situation was contrary for the fan-shaped hole. Fawcett et al. (2013) experimentally investigated the impact of internal crossflow on the coherent unsteadiness within film cooling flows for the cylindrical and shaped cooling holes. Their results illustrated that the orientation of coolant jet ejecting from cylindrical hole could be twisted by 20 degree when the crossflow velocity ratio (related to the bulk jet velocity) reaches to 0.6. At the same magnitude of internal crossflow, the coolant jet ejecting from shaped hole was found to be split in two within the film-hole diffusing exit. Agata et al. (2013a, b) performed investigations to illustrate the effects of turbulence promoting ribs in internal crossflow channel on film cooling performance. Their results showed that the rib orientation is of significant influence on the film cooling performance of gas turbine blade. McClintic et al. (2015) performed an experimental study on the internal crossflow effect for compound-angled film cooling holes. Two different crossflow directions were considered, namely counter crossflow and in-line crossflow respectively. It was demonstrated that the counter crossflow achieves significantly greater adiabatic effectiveness. A shorter hole length was suggested to be advantageous as it could allow for the low momentum recirculation region at the exit. More recently, McClintic et al. (2018, a, b) performed further investigations on the internal crossflow effect, where the velocity ratios of the internal crossflow to the coolant jet were selected as $0.1-2.1$ for the density ratio of 1.2 and $0.1-1.8$ for the density ratio of 1.8 respectively. Their results indicated that the crossflow effect is dominantly governed by how coolant enters the film cooling holes. The influence of internal crossflow on film cooling performance was highly sensitive to its velocity at higher injection rates while much less sensitive at lower injection rates. Li et al. (2017) conducted a numerical simulation to explore the influence of internal crossflow orientations on the film cooling of compound holes. Four crossflow orientations were taken into considerations, including perpendicular-counter, perpendicular-inline, parallel-counter, and parallel-inline. Their results showed that the internal crossflow orientation affects significantly in-hole coolant flow behavior and the film cooling performance as a consequence. The perpendicular-counter and parallel-inline crossflow orientations were demonstrated to produce more uniform velocity distribution at the film-hole exit than the other crossflow orientations, providing a positive influence on the film cooling performance.

As mentioned above, previous researches concerning the internal crossflow effects on film cooling performance were mostly conducted on flat-plate models. With regards to the film cooling at turbine blade surfaces, the mutual interaction between coolant jet and cascade mainstream was certainly more complicated owing to the combined effect of pressure gradient and surface curvature (Gao et al., 2008, 2009; Liu et al., 2010). At the blade suction side, the primary flow acceleration was significantly obvious over the entire suction surface, making the film cooling performance very distinct from that on a flat surface (Arts et al., 1990; Yao et al., 2014). To address more detailed understanding into the internal crossflow effect on the film cooling performance at blade suction side, under the representative engine-simulated environment, a numerical investigation is performed in the current study. Two kinds of film cooling holes (cylindrical and fan-shaped holes) configurations are taken into consideration, under three blowing ratios (1, 2 and 3) and three velocity ratios of the internal crossflow to the coolant jet (0,1 and 2). 


\section{Nomenclature}

$A$ : Area $\left(\mathrm{m}^{2}\right)$

$B r$ : Blowing ratio

$C$ : Blade chord length (m)

$C_{\mathrm{d}}$ : Discharge coefficient

$C_{x}$ : Blade axial chord length (m)

$c_{p}$ : Static pressure coefficient

$d$ : Film hole diameter (m)

$l:$ Film hole length (m)

$m:$ Mass flow-rate $(\mathrm{kg} / \mathrm{s})$

$M a$ : Mach number

$P$ : Cascade pitch (m)

$p$ : Static pressure $(\mathrm{Pa})$

$P_{\text {hole }}$ : Holt-to-hole pitch (m)

$R$ : Gas constant

$R e$ : Reynolds number

$s$ : Streamwise direction

T: Temperature (K)

$U$ : Velocity $(\mathrm{m} / \mathrm{s})$

$v$ : Normal velocity component $(\mathrm{m} / \mathrm{s})$

$V r$ : Crossflow-to-coolant jet velocity ratio

$w$ : Spanwise velocity component $(\mathrm{m} / \mathrm{s})$

$x$ : Axial direction

$y$ : Lateral or spanwise direction

$z$ : Normal direction

Greek Letters

$\alpha$ : Inclination angle of film hole $\left(^{\circ}\right)$

$\beta$ : Laterally diffused angle of fan-shaped hole $\left({ }^{\circ}\right)$

$\delta$ : Inflow angle $\left(^{\circ}\right)$

$\gamma$ : Ratio of specific heat

$\eta_{\text {ad: }}$ : Adiabatic film cooling effectiveness

$\mu$ : Dynamic viscosity $\left(\mathrm{N} \cdot \mathrm{s} / \mathrm{m}^{2}\right)$

$\theta$. Stagger angle $\left(^{\circ}\right)$

$\rho:$ Density $\left(\mathrm{kg} / \mathrm{m}^{3}\right)$

Subscripts

aw: Adiabatic wall

c: Crossflow

j: Coolant jet

l: Laterally-averaged

t: Total

$\infty$ : Mainstream 


\section{Computational Procedures}

\subsection{Brief description of physical model}

In the current study, a simplification is made in the physical model of turbine guide vane. The blade model is made by simply stacking a two-dimensional midspan profile extracted from a three dimensional geometry of an original blade. Its sectional profile and main parameters are shown in Figure 1(a) and Table 1 respectively, which is taken from the previously researched model presented by Yao et al. (2014). A single row of film cooling holes is located at an axial position of $69 \% C_{\mathrm{x}}$ on the guide vane suction surface.

Two types of film-hole configurations (cylindrical and fan-shaped) are concerned in the current study, as schematically shown in Figure 1(b). For both film-hole configurations, the diameter of film-hole $(d)$ is $0.6 \mathrm{~mm}$, the hole-to-hole pitch $\left(P_{\text {hole }}\right)$ is selected as $2.5 d$ referring to Yao et al .(2009) and Heidmann et al. (1999), the inclination angle $(\alpha)$ is $30^{\circ}$ in the streamwise direction, and the length-to-diameter ratio $(l / d)$ is 3 . For the fan-shaped hole, the lateral expansion is orientated at $1 d$ downstream the hole inlet. It has a laterally diffused angle $(\beta)$ of $14^{\circ}$ within an expansion length of $2 d$.

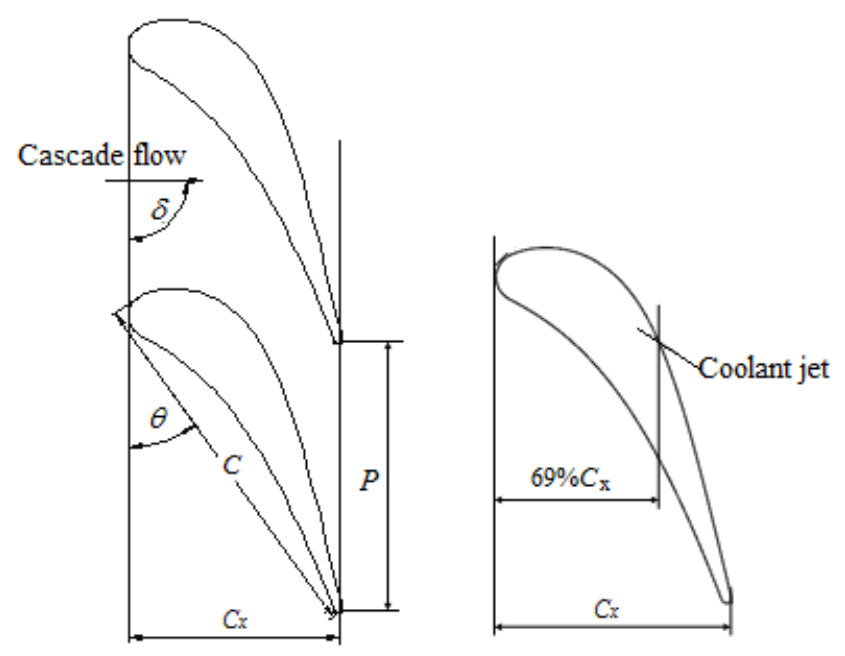

(a) guide vane profile

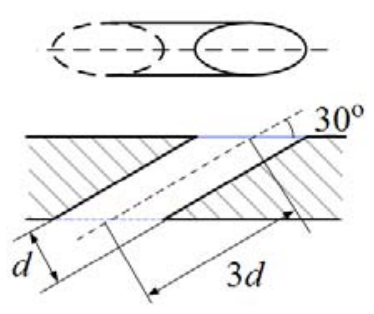

cylindrical

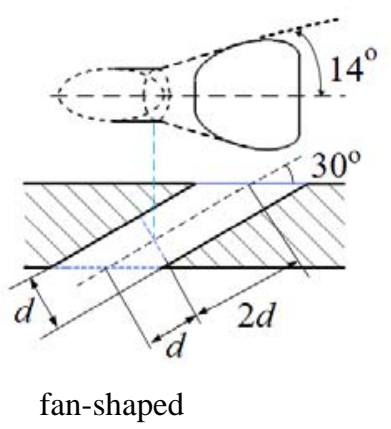

(b) film cooling holes

Fig.1 Schematic diagram guide vane and film cooling holes.

Table 1 Main parameters of guide vane.

\begin{tabular}{l|c}
\hline \hline Parameter & Value \\
\hline Chord length, $C$ & $74.4 \mathrm{~mm}$ \\
Axial chord length, $C_{x}$ & $42.3 \mathrm{~mm}$ \\
Cascade pitch, $P$ & $53.6 \mathrm{~mm}$ \\
Inflow angle, $\delta$ & $90^{\circ}$ \\
Stagger angle, $\theta$ & $35.7^{\circ}$ \\
\hline
\end{tabular}




\subsection{Computational domain and boundaries}

Considering that the cascade flow is of periodicity, one cascade pitch is chosen as the computational domain. Besides, as the current study focuses attention on the demonstration of internal crossflow effect on film cooling performance, the endwall influences on cascade flow and film cooling are not taken into considerations. Thus, a spanwise segment of blade is chosen for building up the computational domain where only one film cooling hole is involved in, by applying two periodic planes at each side of the cascade channel. The coolant flow is directed into the internal coolant channel from the $-y$ side and exited from the $+y$ side, as seen in Figure 2(a). To eliminate the inlet and outlet effects of internal crossflow, extended pipes with ten times of hydraulic diameters of internal coolant channel are applied at both spanwise sides of the computational domain. The coordinates $s, y$ and $z$ denote the streamwise direction along the curved surface, spanwise direction and normal direction to the blade surface, respectively. For the situation without presence of internal crossflow, a plenum coolant-fed mode is adopted, as seen in Figure 2(b).

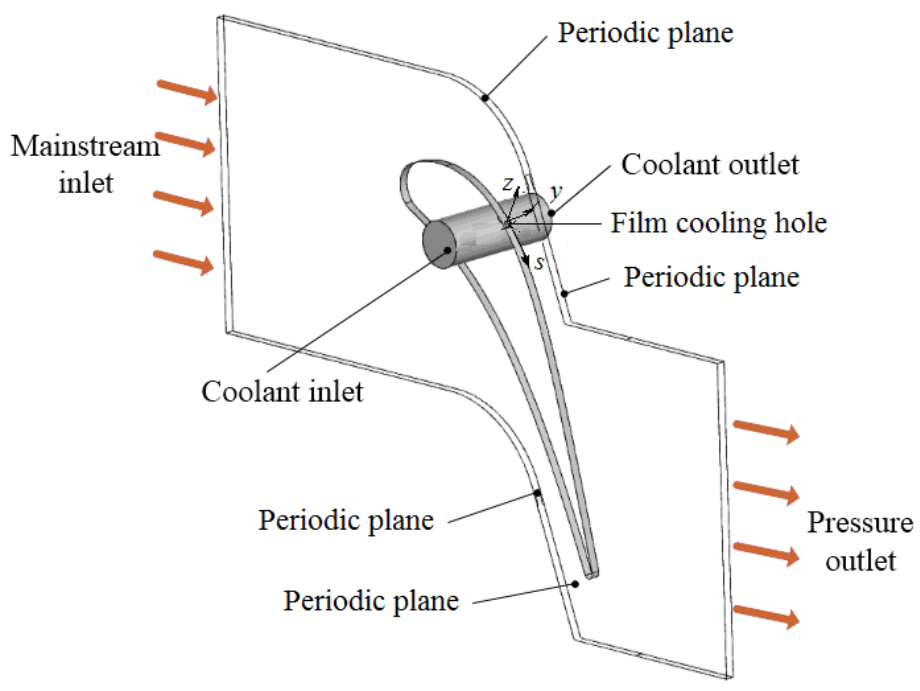

(a) with internal crossflow

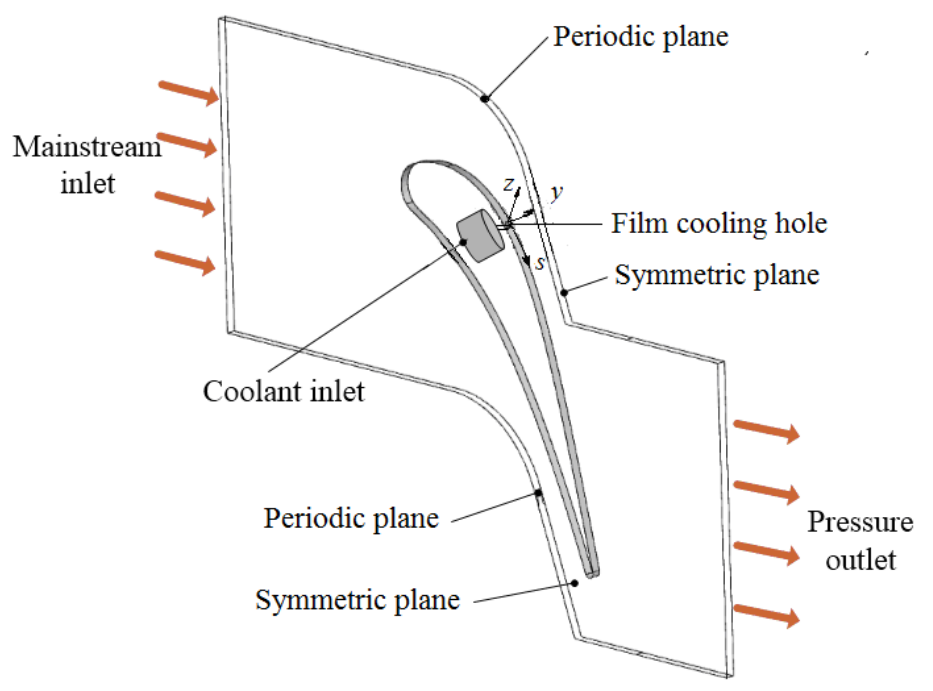

(b) without internal crossflow

Fig.2 Schematic diagram of computational domain.

The computational domain consists of three flow regions. They are cascade passage, internal crossflow channel and film cooling holes. Accordingly, the boundary conditions in computation are specified as the follows.

Cascade passage: a mass-flow inlet is applied at the cascade entrance, which is specified in accordance with Reynolds number $\left(R e_{\infty}\right)$ of $5 \times 10^{5}$. Here the mainstream or primary flow Reynolds number is defined as Eq.(1) where 
the characteristic length is chosen as the blade chord length. The total temperature of primary flow entering into the cascade channel $\left(T_{\mathrm{t}, \infty}\right)$ is $2100 \mathrm{~K}$. According to the previous works on the free-stream turbulence effects (such as $8.3 \%$ by Hylton et al., 1983; 6\% by Arts et al., 1990; 3.6\% 11\% by Saumweber et al., 2003; 10\% for the primary flow and $5 \%$ at coolant inlet by Wang et al., 2013; 5\% by Alameldin et al., 2014), a moderate value of turbulence intensity level (7.5\%) is implemented in the current study. And the turbulence length scale is selected as 3\% of the blade chord length. The flow outlet boundary of cascade channel is set as a pressure outlet with the fixed static pressure $\left(p_{\text {outlet }}\right)$ of $1.3 \mathrm{MPa}$. For the periodic planes and symmetric planes enclosing the computational domain, the correspondingly periodic conditions and symmetric conditions are applied respectively.

$$
\operatorname{Re}_{\infty}=\frac{\rho_{\infty} U_{\infty} C}{\mu_{\infty}}
$$

where $\rho_{\infty}, U_{\infty}$ and $\mu_{\infty}$ are density, velocity and dynamic viscosity of the primary flow respectively at the cascade entrance.

Coolant passage: for the situation with the presence of internal crossflow, the mass-flow rates are specified at both the inlet and the outlet of internal crossflow channel. The respective mass-flow rates are determined simultaneously according to crossflow-to-coolant jet velocity ratio $(V r)$ and blowing ratio $(B r)$, defined as Eqs.(2) and (3) respectively. For the situation without the presence of internal crossflow, a mass-flow rate is specified at the inlet of coolant-fed plenum, according to blowing ratio $(B r)$ only. The total temperature of cooling air $\left(T_{\mathrm{t}, \mathrm{c}}\right)$ is set as $900 \mathrm{~K}$. The turbulence intensity level is selected as $5 \%$ and the turbulence length scale is selected as $3 \%$ of the inlet hydraulic diameter.

$$
\begin{gathered}
V r=\frac{U_{c}}{U_{j}} \\
B r=\frac{\rho_{j} U_{j}}{\rho_{\infty} U_{\infty}}
\end{gathered}
$$

where $U_{\mathrm{c}}$ is the mean velocity of internal crossflow passing through the film cooling holes. $\rho_{\mathrm{j}}$ and $U_{\mathrm{j}}$ are density and mean velocity of coolant jet at film-hole inlet. As the cross-sectional area is varied for the shaped holes, to ensure the same coolant usage of the shaped holes as the cylindrical holes for comparisons, the blowing ratio $(\mathrm{Br})$ is defined according to the mean parameters at the film-hole inlet. In the current investigation, five blowing ratios are selected as $B r=0.5,1.0,1.5,2.0$ and 3 respectively, and three velocity ratios of the internal crossflow to the coolant jet are selected as $V r=0,1$ and 2 respectively, where $V r=0$ denotes the situation without presence of internal crossflow.

All of the solid surfaces are treated as the adiabatic no-slip condition. With regards to the film cooling holes, the inlet and outlet are defined as the interfaces with internal crossflow and cascade flow respectively.

\subsection{Computational scheme}

Three-dimensional steady-state simulations are conducted on the Reynolds time averaged (RANS) approach by using Fluent-CFD software (Ansys-Fluent 14.0). The SIMPLEC algorithm and QUICK scheme are adopted for solve of pressure-velocity coupling and spatial discretization of convection terms in the governing equations, respectively. In the current study, an ideal air approach is applied for both the cascade flow and the coolant flow. Therefore, the ideal-gas based density, Kinetic-theory based specific heat and thermal conductivity and Sutherland law based viscosity are set in the computations. The turbulence model for the turbulence closure is selected referring previous works (Harrison and Bogard, 2008; Silieti et al., 2004, 2009; Ely and Jubran, 2009). For example, Silieti et al. (2004, 2009) examined multiple turbulence models in the use of film cooling prediction and suggested that realizable k- $\varepsilon$ turbulence model is a fairly reasonable choice for offering good predictions of film cooling performance. Therefore, realizable k- $\varepsilon$ turbulence model along with the enhanced wall treatment which makes use of a two-layer approach (provided in Fluent-CFD software) is adopted to model the turbulence in the current numerical simulations.

Multi-block computational meshes are generated by using ICEM software. Figure 3 shows the local computational grids. In order to accurately solve the near-wall flow, computational meshes are refined near the solid surfaces. Systematic mesh sensitivity is evaluated in advance for selecting the reasonable grid dividing. As a consequence, a grid system with approximate 1.5 million grids is finally selected for the internal crossflow situations where the corresponding maximum $y^{+}$is less than 1.0. Similarity, approximately 1.34 million grids are finally selected under plenum-fed scheme (that is $V r=0$ ). 


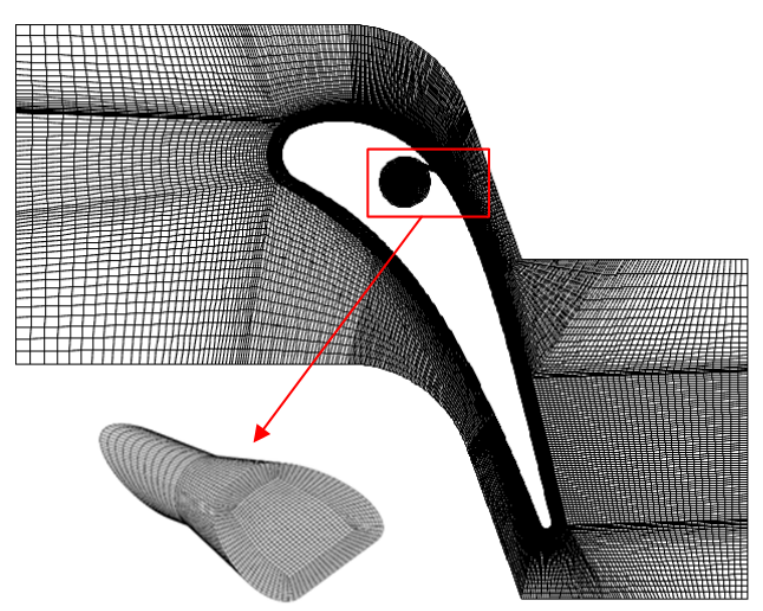

Fig.3 Computational grids

The convergence criterion is regarded to be met when the residual reaches $10^{-5}$ and the film-cooled surface temperature shows no observable change for additional 50 iterations simultaneously.

Two main characteristic parameters associated with the film cooling performance are adiabatic film cooling effectiveness $\left(\eta_{\mathrm{ad}}\right)$ and discharge coefficient $\left(C_{\mathrm{d}}\right)$. They are defined as the follows.

$$
C_{d}=\frac{m_{j, r}}{m_{j, i}}=\frac{\eta_{a d}=\frac{T_{\infty}-T_{a w}}{T_{\infty}-T_{c}}}{A_{j} p_{t, c}\left(\frac{p_{\infty}}{p_{t, c}}\right)^{\frac{(\gamma+1)}{\gamma}} \sqrt{\frac{m_{j, r}}{(\gamma-1) R T_{t, c}}\left(\left(\frac{p_{t, c}}{p_{\infty}}\right)^{\frac{\gamma-1}{\gamma}}-1\right)}}
$$

where $T_{\infty}, T_{\mathrm{c}}$ and $T_{\mathrm{aw}}$ are the mainstream temperature, coolant temperature and adiabatic wall temperature respectively. $m_{\mathrm{j}, \mathrm{r}}$ and $m_{\mathrm{j}, \mathrm{i}}$ are the actual mass flow rate and the ideal mass flow rate through the film holes, respectively. $\gamma$ is the ratio of specific heat and $R$ is the gas constant. $A_{\mathrm{j}}$ is the total inlet area of film cooling holes. $p_{\mathrm{t}, \mathrm{c}}$ and $T_{\mathrm{t}, \mathrm{c}}$ are the total pressure and total temperature of coolant flow reapectively. $p_{\infty}$ is the mean static pressure at the film cooling hole outlet.

By the line-average within one hole-to-hole pitch $\left(P_{\text {hole }}=2.5 d\right)$, the laterally-averaged adiabatic film cooling effectiveness $\left(\eta_{\text {ad,av }}\right)$ is obtained.

\subsection{Validation of computational scheme}

For the purpose of validation of current numerical scheme, two examples are carried out in advance.

The first computational model is taken from the work of Arts et al. (1990) where a benchmark VKI model of linear turbine guide blade cascade was presented. In this simulation, a turbulence intensity level of $6 \%$ is selected in accordance with that experimental data. The computed Mach number contour in a cascade passage and the static pressure distribution on blade surface are presented in Figure 4. Due to the flow turning of primary flow in the cascade channel, the primary flow experiences significant acceleration over nearly entire suction surface. While at the pressure side, the primary flow acceleration mainly occurs near the blade trailing, as seen in Figure 4(a). At the leading edge of blade, the static pressure is the same as the total pressure of primary flow at the cascade entrance due to the flow stagnation, as illustrated in Figure 4(b). On the blade pressure and suction surfaces, the pressure coefficient distributions take on distinct variations. At the suction side, the static pressure decreases rapidly from the leading edge to the middle chord, owing to the rapid acceleration of the primary flow in the vicinity of blade suction surface. The primary flow reaches the maximum speed around $x / C_{\mathrm{x}}=0.7$ and then decelerates toward the trailing edge. While at the pressure side, the static pressure decreases slowly from the leading edge to an axial dimensionless distance of about $x / C_{\mathrm{x}}=0.6$ and then rapidly from this axial dimensionless distance to the trailing edge. By comparison with the experimental data of Arts et al. (1990), the computed static pressure distribution is satisfactory. 


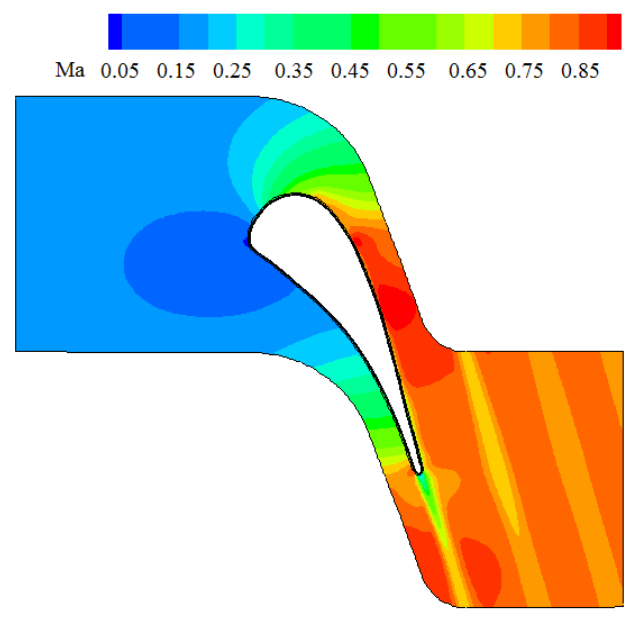

(a) Mach number contour

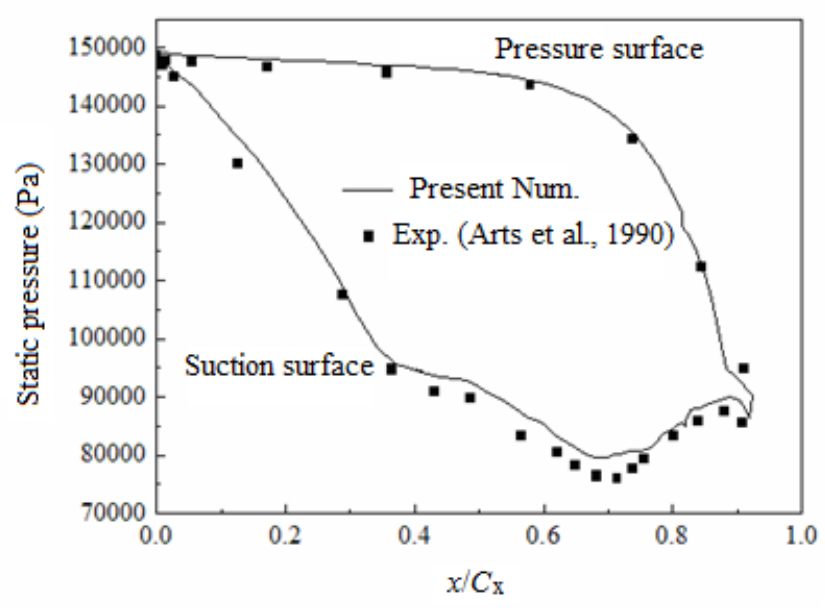

(b) static pressure distribution on blade surface

Fig.4 Validation of flow field inside a linear turbine guide vane cascade

Another computational model is taken from the work of Gritsch et al. (2003) where an effect of internal coolant crossflow was presented for the fan-shaped film-cooling holes on a flat plate. In this simulation, a turbulence intensity level of $2 \%$ is selected in accordance with that experimental data. Beside, an internal Mach number $\left(\mathrm{Ma}_{\mathrm{c}}\right)$ of 0.3 and a blowing ratio of 0.5 are selected. Figure 5 presents the comparisons between the current numerical results and the experimental results of Gritsch et al. (2003). Either for the local film cooling effectiveness or the laterally-averaged film cooling effectiveness distributions on the suction surface, the computed results are generally in good agreements with the corresponding experiment results, with a maximum difference within $10 \%$.

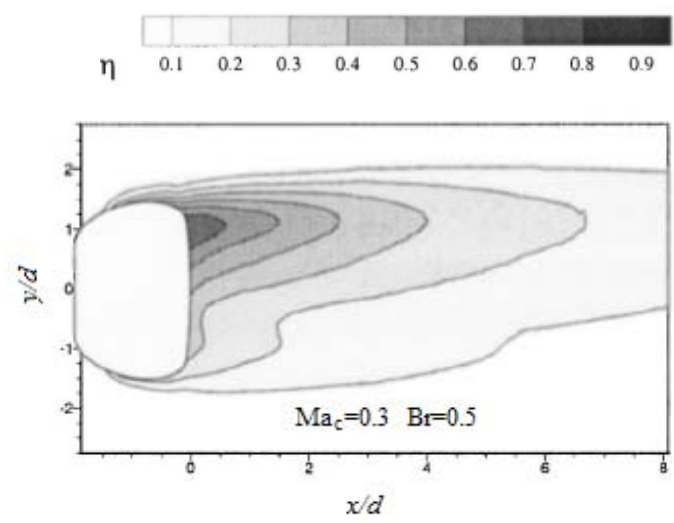

experiment by Gritsch et al. (2003)

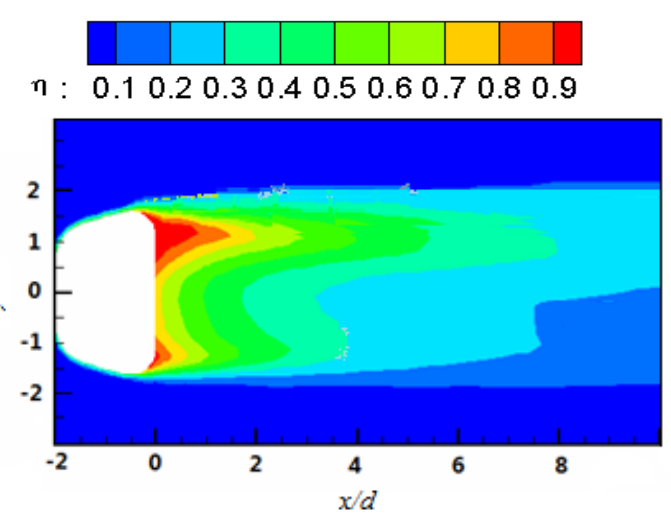

current computation

(a) local film cooling effectiveness

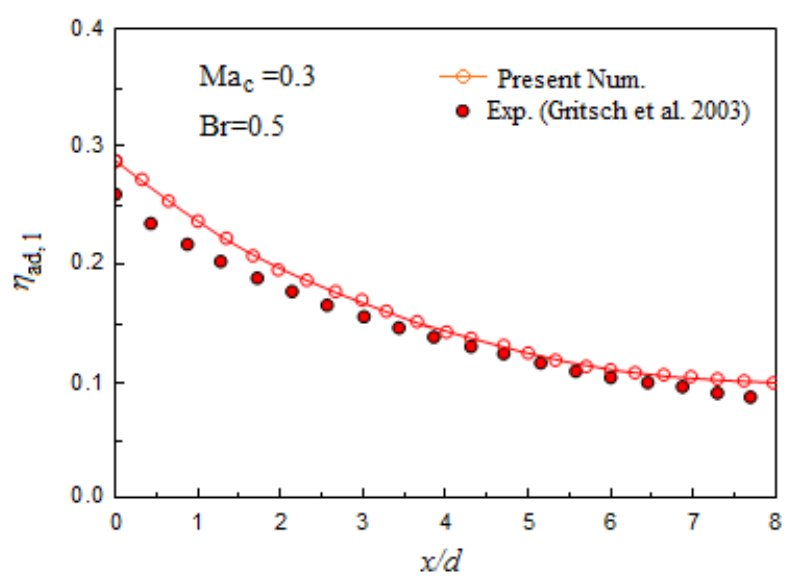

(b) laterally-averaged film cooling effectiveness

Fig.5 Validation of fan-shaped hole film cooling in the presence of internal crossflow 


\section{Results and Discussions}

\subsection{Detailed flow fields}

Figure 6 presents the Mach number contours in the cascade channel and static pressure coefficient distribution $\left(c_{p}=\left(p_{s}-p_{t \infty}\right) /\left(0.5 \rho_{\infty} U_{\infty}^{2}\right)\right.$, here $P_{\mathrm{s}}$ is the static pressure on the turbine surface) at the vane middle plane, under $\mathrm{Br}=2$ and $\mathrm{Vr}=0$. At the suction side, the primary flow accelerates rapidly from the leading edge of blade toward the film-hole location. Under the impact of coolant injection, the static pressure coefficient experiences a sudden variation in the vicinity of film cooling hole. Then the primary flow decelerates a little toward the trailing edge of blade. While at pressure side, the static pressure changes a little from the leading edge to about $x / C_{\mathrm{x}}=0.67$ and then falls off rapidly toward the trailing edge. The above flow features in a turbine cascade are in good agreement with the previous finding of Arts et al. (1990).

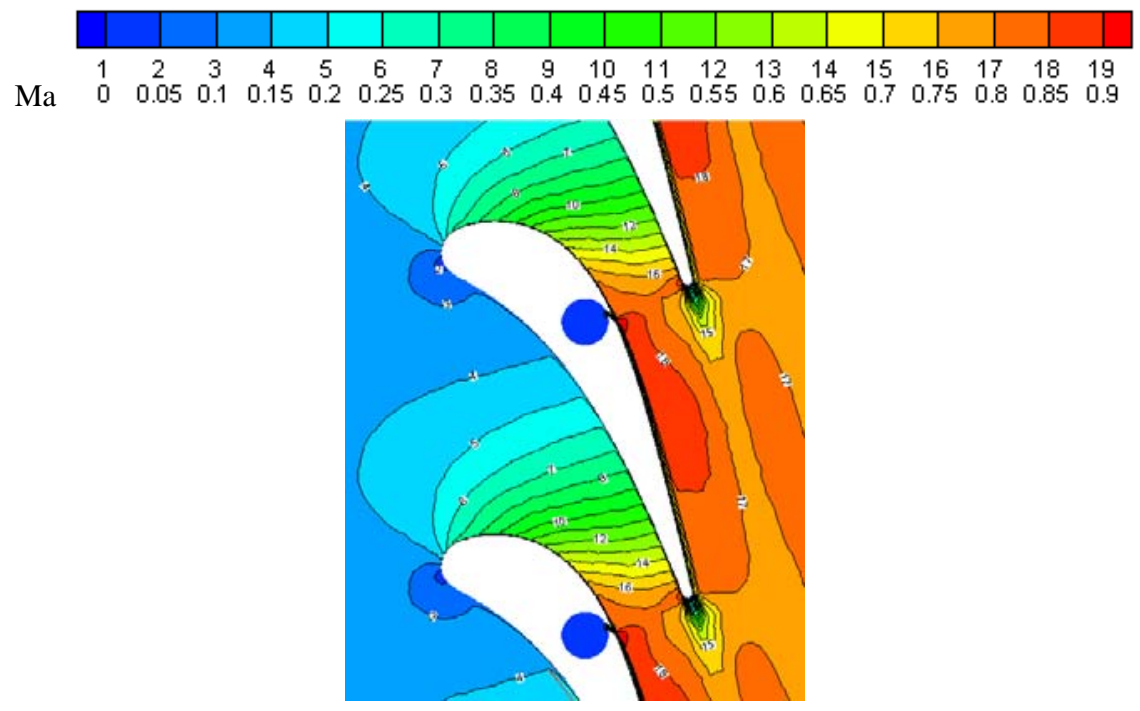

(a) Mach number contours

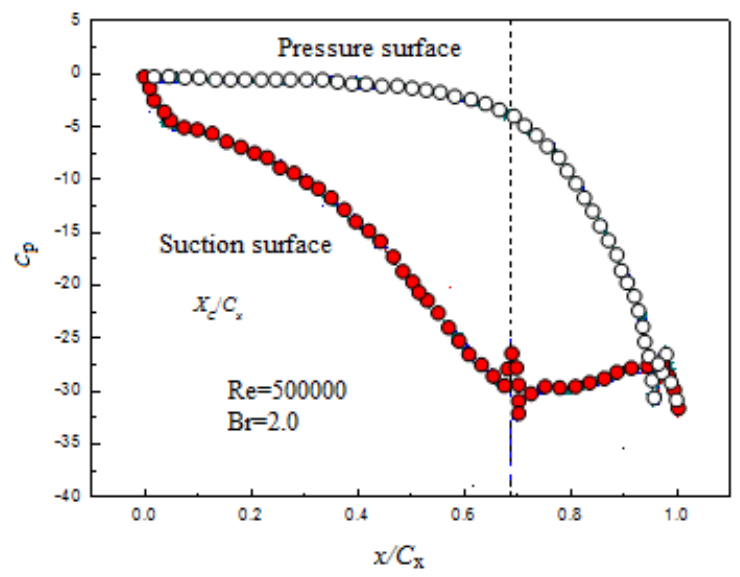

(b) pressure coefficient distribution

Fig.6 Mach number contours and static pressure distribution on blade surface

Figure 7 and Figure 8 display the coolant flow streamlines in vicinity of film cooling hole, and the velocity component contours at hole exit, respectively, under $B r=2.0$ without internal crossflow. For the plenum coolant-fed mode, the jetting flow is observed inside film cooling hole, as seen in Figure 7. This is a common phenomenon for the angled-hole film cooling due to the coolant flow turning at film-hole entrance (Leylek and Zerkle, 1994; Kohli and Thole, 1998). The jetting effect makes the coolant jet velocity distribution at film-hole exit very un-uniform. As seen in Figure 8(a), an ejecting zone with obviously high normal velocity component occurs near the film-hole trailing edge. Compared to cylindrical hole, the fan-shaped hole reduces significantly normal velocity component of coolant jet owing to its diffusing geometric feature. With regard to the spanwise velocity component, as seen in Figure 6(b), its 
maximum absolute value occurs at both sides of film cooling hole near the leading edge. As the fan-shaped hole takes on lateral expansion, the spanwise flow of coolant jet is evidently enhanced. Consequently, the fan-shaped hole provides a weaker normal velocity component but a stronger spanwise velocity component, playing an anti-kidney vortices role on the mutual interaction between coolant jet and mainstream.

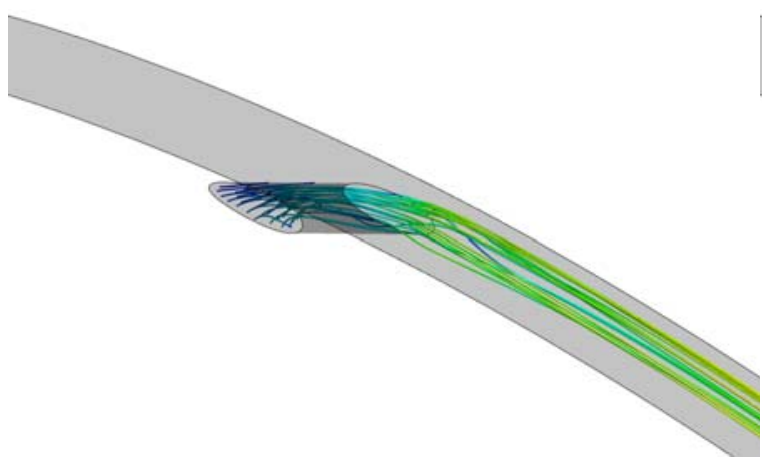

(a) cylindrical hole

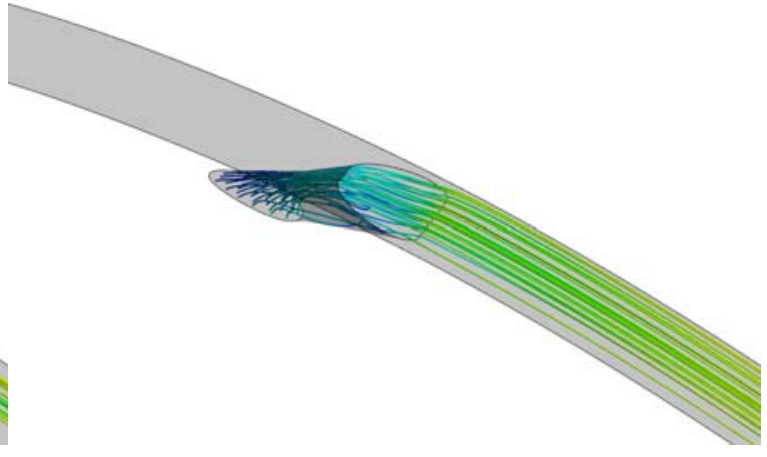

(b) fan-shaped hole

Fig.7 Coolant flow streamlines under $\mathrm{Br}=2.0$ and $\mathrm{Vr}=0$.

$w / U_{\infty} \quad \begin{array}{llllllllllllllll} & 0.1 & 0.2 & 0.3 & 0.4 & 0.5 & 0.6 & 0.7 & 0.8 & 0.9 & 1\end{array}$

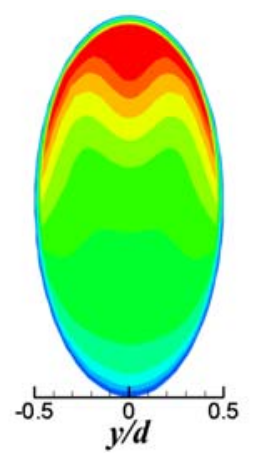

(a-1) cylindrical hole

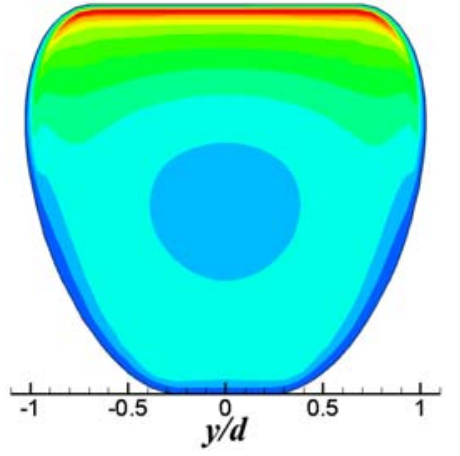

(a-2) fan-shaped hole

(a) normal velocity component

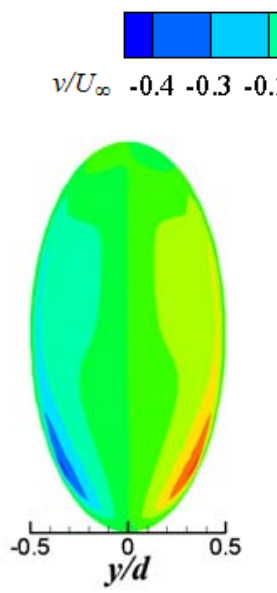

(b-1) cylindrical hole
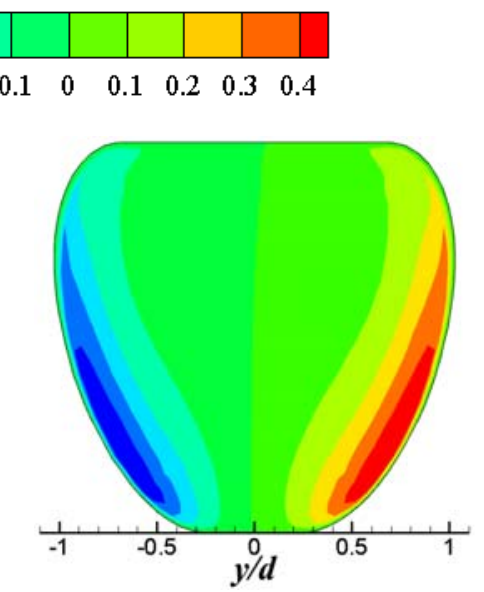

(b-2) fan-shaped hole

(b) spanwise velocity component

Fig.8 Velocity distributions under $\mathrm{Br}=2.0$ and $\mathrm{Vr}=0$.

Figure 9 displays the coolant flow streamlines under $B r=2.0$ and $V r=1.0$. It is seen that the combinition of internal 
crossflow effect and entrance jetting effect makes the coolant flow inside film hole more complicated. A helical flow feature is demonstrated dominantly. The coolant flow after ejection from the film cooling hole is pushed toward one side in accordance to the internal flow direction.

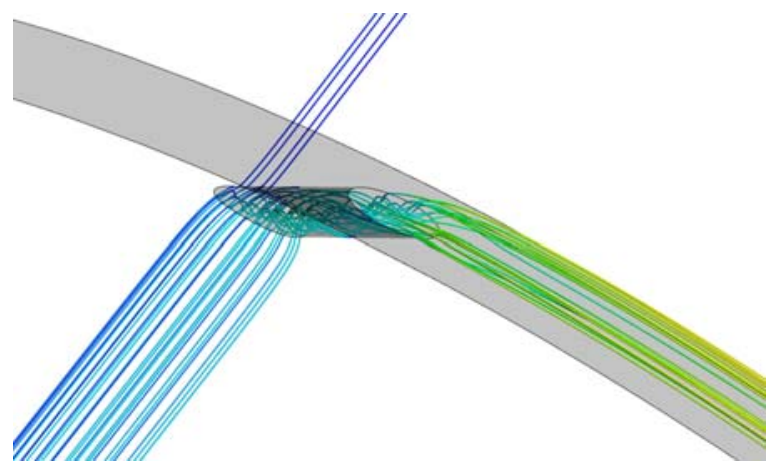

(a) cylindrical hole

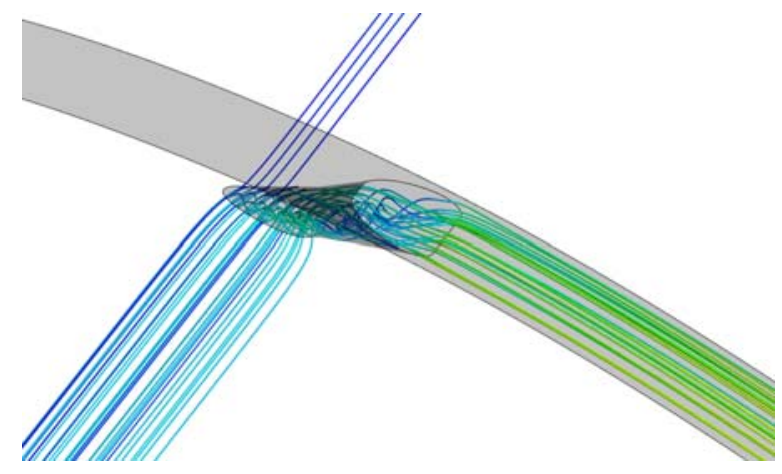

(b) fan-shaped hole

Fig.9 Coolant flow streamlines under $\mathrm{Br}=2.0$ and $\mathrm{Vr}=1.0$.

Figure 10 presents the velocity distribution at film cooling hole outlet under $B r=2.0$ and $V r=1.0$. Due to the internal crossflow effect, the ejecting velocity of coolant jet at film-hole outlet takes on an obviously un-asymmetric distribution. For the cylindrical hole, as seen in Figure 10(a-1), the local zone with high normal velocity component appears at the $+y$ side of film-hole trailing edge. At the central zone of film-hole, a low-normal-velocity zone is formed. With regard to the jet flow in the spanwise direction, it is found that the leading zone of film cooling hole is mostly occupied by the nagative spanwise velocity component, as seen in Figure 10(b-1), suggesting that the coolant jet issuing from the film-hole leading zone flows dominantly along the $-y$ direction (opposite to the internal crossflow direction). In the vicinity of film-hole trailing edge, a local zone with high positive velocity component appears close to the $+y$ side. Considering that the coolant jet has a high normal velocity component in the vicinity of film-hole trailing edge, the massflow distribution is certainly concentrated at this zone. Therefore, the high positive velocity component appearring close to the $+y$ side in the vicinity of film-hole trailing edge is contributed to the jet deflection in accordance with to the internal flow direction. For the fan-shaped hole, as seen in Figure 10(a-2), the internal crossflow seems have little influence on the normal flow of coolant jet in the vicinity of film-hole trailing edge. However, in the vicinity of film-hole leading edge, the fan-shaped hole produces higher normal jet velocity when compared to the situation without internal flow. In comparison with the situation without internal flow, the spanwise flow of coolant jet at $-y$ side is enhanced, as seen in Figure 10(b-2). The high nagative-velocity-component zone invades toward the $+y$ side, pressing the local zone with a high positive-velocity-component near $+y$ side of film cooling hole, and leading to a local zone with a high positive-velocity-component near the film-hole trailing edge.

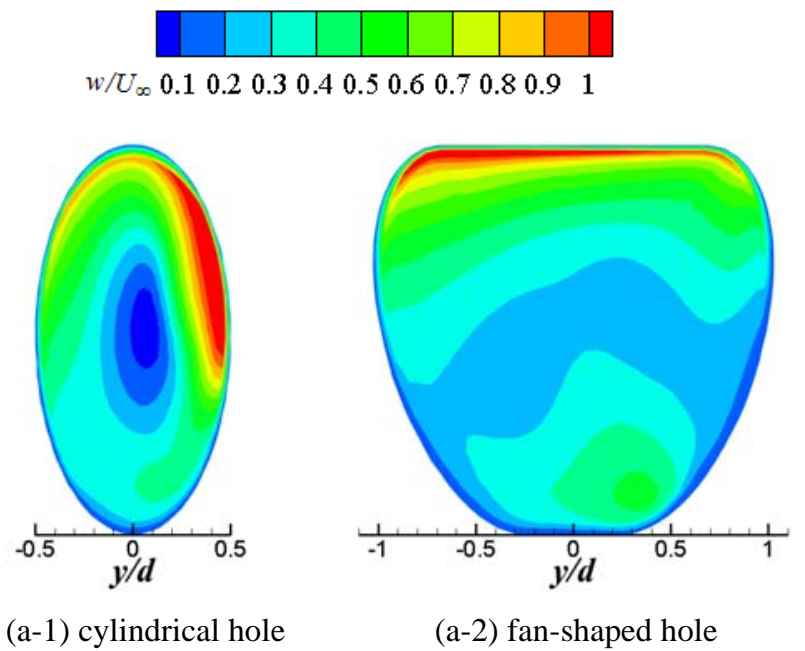

(a) normal velocity component 


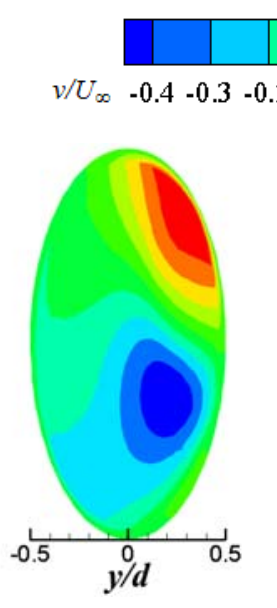

(b-1) cylindrical hole

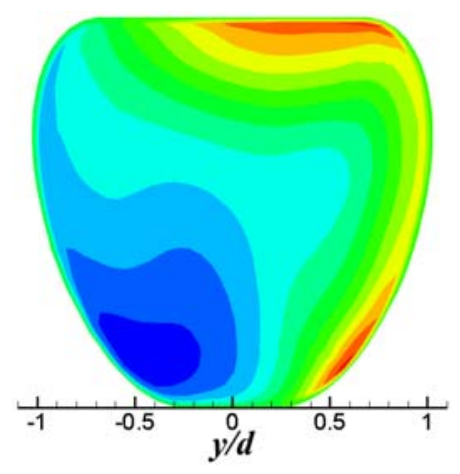

(b-2) fan-shaped hole

(b) spanwise velocity component

Fig.10 Velocity distributions under $\mathrm{Br}=2.0$ and $\mathrm{Vr}=1.0$.

$$
w / U_{\infty} 0.1 \quad 0.20 .3 \quad 0.4 \quad 0.5 \quad 0.6 \quad 0.70 .80 .9 \quad 1
$$

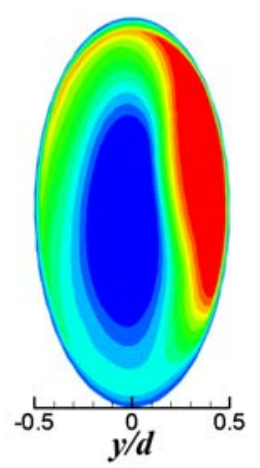

(a-1) cylindrical hole

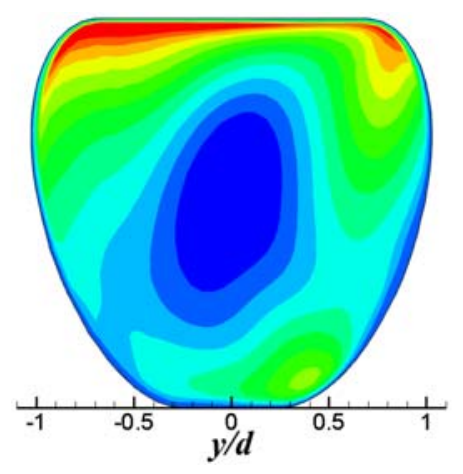

(a-2) fan-shaped hole

(a) normal velocity component

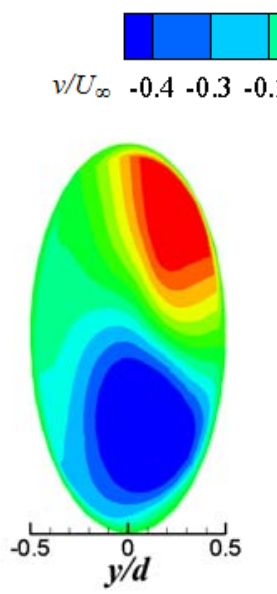

(b-1) cylindrical hole

(b) spanwise velocity component

Fig.11 Velocity distributions under $\mathrm{Br}=2.0$ and $\mathrm{Vr}=2.0$.

Figure 11 presents the coolant jet velocity distribution at film-hole outlet under $B r=2.0$ and $V r=2.0$. Under a high crossflow-to-coolant jet velocity ratio, the internal crossflow effect behaves more strongly, producing a widely 
concentrated low-normal-velocity-component zone in the film-hole cernter. Meanwhile, the local zone with normal velocity is increased obviously, as seen in Figure 11(a). The invasion of nagative-spanwise-velocity-component zone toward the $+y$ side of film cooling hole is also enhanced, as seen in Figure 11(b).

Figure 12 shows the internal crossflow effect on mutual interaction between coolant jet and mainstream under $B r=2.0$. Due to the internal screwing flow of coolant jet inside film cooling hole, the symmetric distribution of kidney vortice pair to the film-hole centerline is distroied. Of particular interst is that the lift of kidney vortice is more seriously at $+y$ side for cylindical hole but the situation is opposite for fan-shaped hole. Under a high crossflow-to-coolant jet velocity ratio, the kidney vortice at $-y$ side is even destroyed for cylindrical hole, as seen in Figure 12(a-2), which is suggested to be contributive to the strong negative lateral flow of coolant jet, as displayed in Figure 11(b-1). In comparison with the cylindrical hole, the effect of crossflow-to-coolant jet velocity ratio on the mutual interaction between coolant jet and primary flow downstream the film cooling hole is relatively weaker for the fan-shaped hole.

Temperature(K) 11001200130014001500160017001800

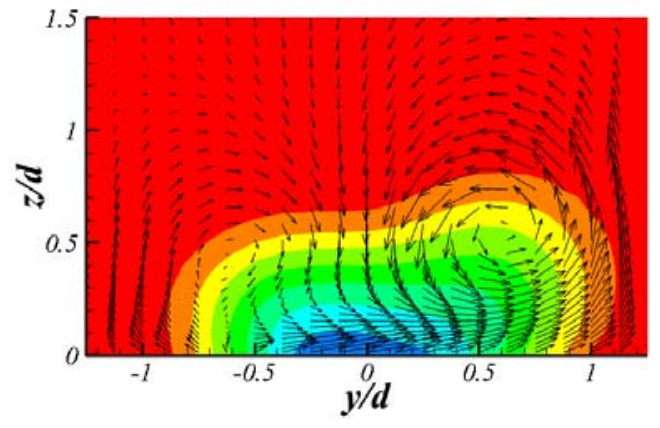

(a-1) $\mathrm{Vr}=1.0$

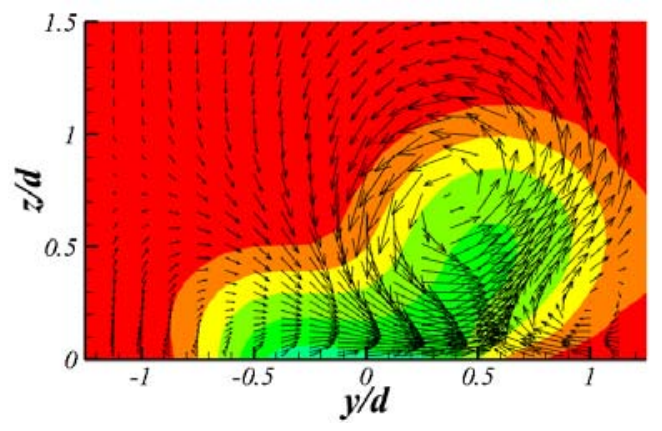

(a-2) $\mathrm{Vr}=2.0$

(a) cylindrical hole

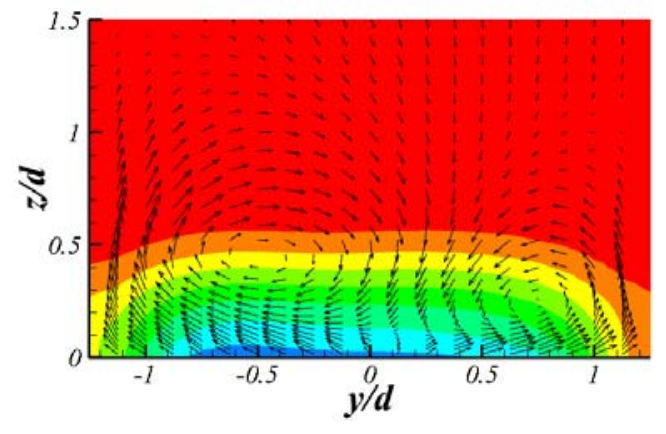

(b-1) $\mathrm{Vr}=1.0$

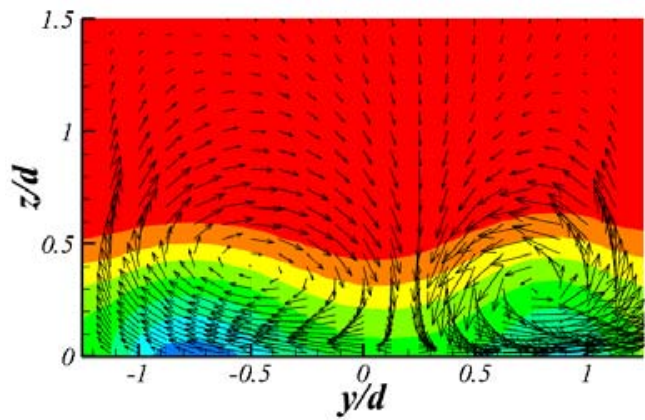

(b-2) $\mathrm{Vr}=2.0$

(b) fan-shaped hole

Fig.12 Streamlines and temperature contours in normal section at $\mathrm{s} / \mathrm{d}=5$ under $\mathrm{Br}=2.0$ in presence of internal crossflow

Figure 13 presents the internal crossflow effect on discharge coefficient of film cooling holes. As the fan-shaped hole has a diffusing exit, it surely achieves higher discharge coefficient in comparison with the cylindrical hole under the same flow conditions. With the presence of internal crossflow, the coolant flow turning at film-hole entrance is evidently aggravated. Besides, the coolant flow inside film cooling hole is more complicated. These factors are expected to increase the pressure drop across the hole, resulting in the reduction of discharge coefficient of film cooling hole. From Figure 13, it is also found the crossflow-to-coolant jet velocity ratio of $V r=1.0$ has a little influence on the discharge coefficient of film cooling hole. However, under a high crossflow-to-coolant jet velocity ratio of $V r=2.0$, approximately 15\% 20\% reduction of discharge coefficient is produced for the cylindrical hole, and $20 \% \sim 27 \%$ reduction for the fan-shaped hole. 


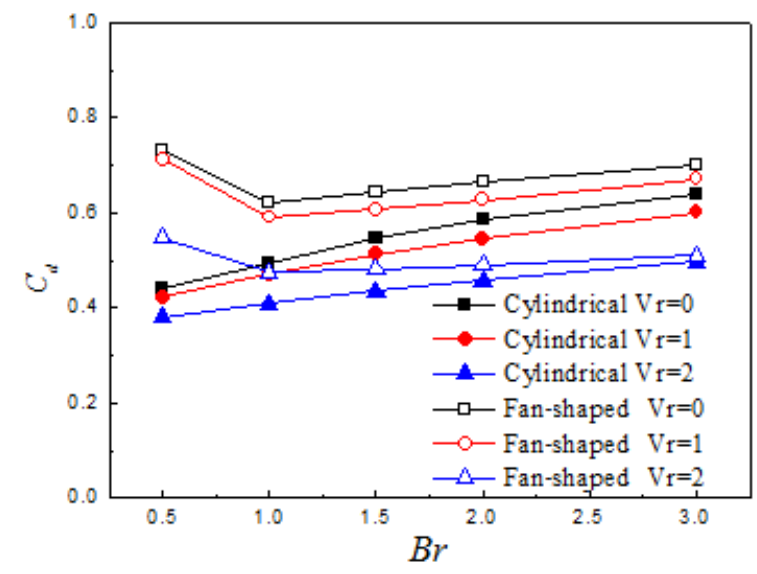

Fig.13 Effect of internal crossflow on the discharge coefficient

\subsection{Film cooling effectiveness}

Figure 14 Figure 16 present local adiabatic film cooling effectiveness distributions under three typical blowing ratios, respectively. At the suction side of blade, as the primary flow is accelerated over nearly entire surface, the coolant jet penetration is expected to be effectively suppressed. Therefore, at the suction side, suitable increase of blowing ratio is helpful for enhancing the film cooling effectiveness, either for the fan-shaped hole or cylindrical hole, because the downward flow momentum of coolant jet is enhanced with the increase of blowing ratio whereas the coolant jet normal penetration is a little affected due to the accelerated primary flow.

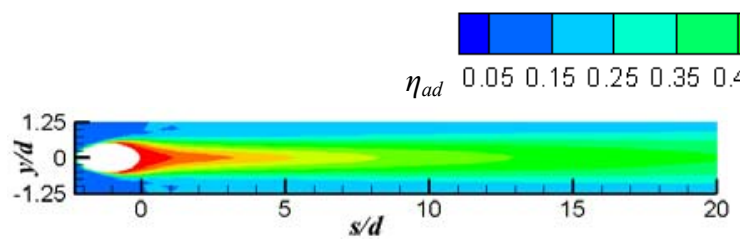

(a-1) cylindrical hole

(a) no crossflow

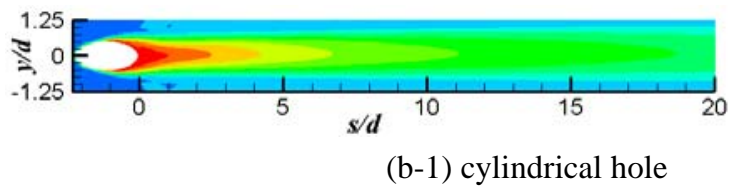

(b-1) cylindrical hole

(b) $\mathrm{Vr}=1.0$

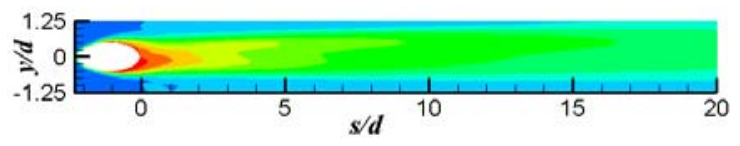

(c-1) cylindrical hole

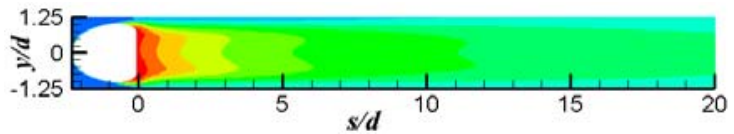

(b-2) fan-shaped hole

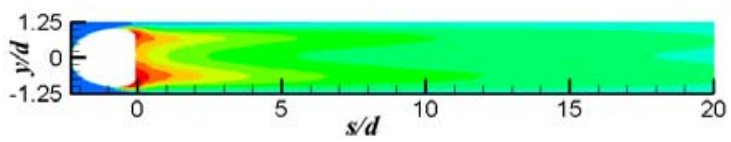

(c-2) fan-shaped hole

(c) $\mathrm{Vr}=2.0$

Fig.14 Adiabatic film cooling effectiveness distributions under $B r=1.0$

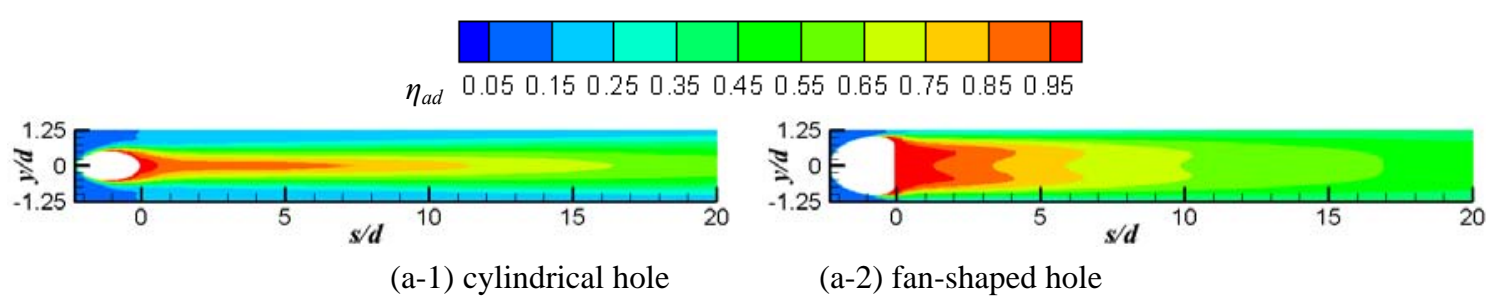

(a) no crossflow 


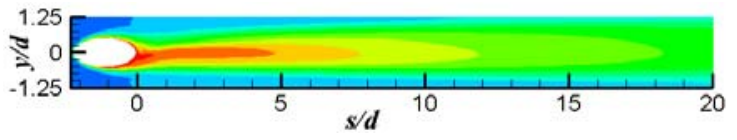

(b-1) cylindrical hole

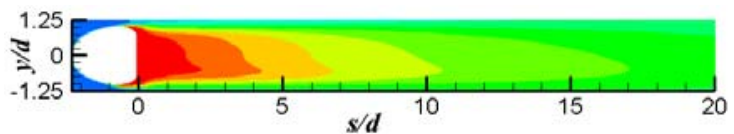

(b-2) fan-shaped hole

(b) $\mathrm{Vr}=1.0$

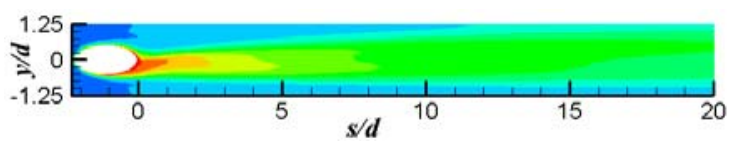

(c-1) cylindrical hole

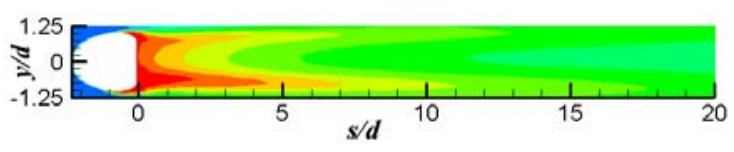

(c-2) fan-shaped hole

(c) $\mathrm{Vr}=2.0$

Fig.15 Adiabatic film cooling effectiveness distributions under $\mathrm{Br}=2.0$

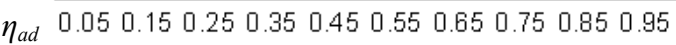

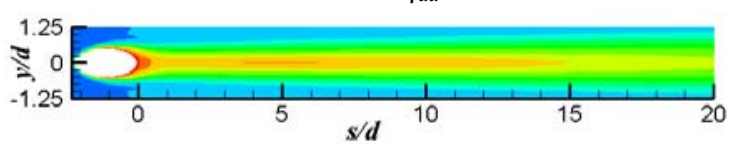

(a-1) cylindrical hole

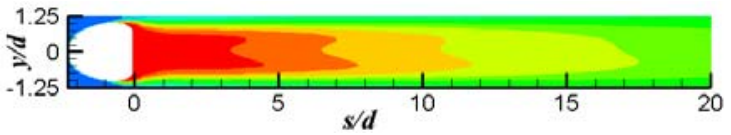

(a-2) fan-shaped hole

(a) no crossflow

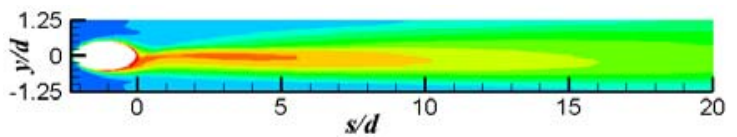

(b-1) cylindrical hole

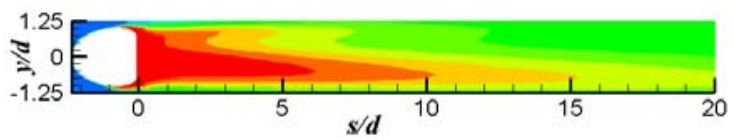

(b-2) fan-shaped hole

(b) $\mathrm{Vr}=1.0$

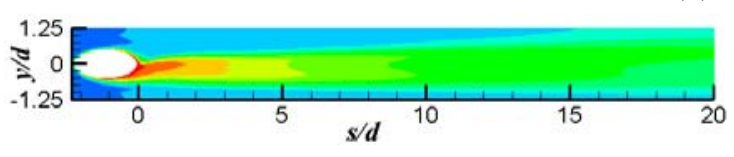

(c-1) cylindrical hole

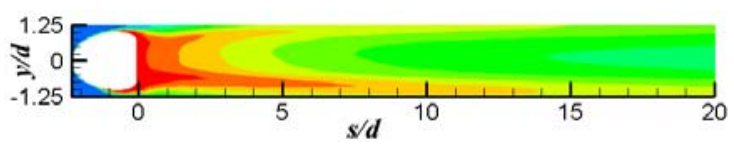

(c-2) fan-shaped hole

(c) $\mathrm{Vr}=2.0$

Fig.16 Adiabatic film cooling effectiveness distributions under $B r=3.0$

Following the influence roles of internal crossflow on mutual interaction between the coolant jet and the primary flow, the adiabatic film cooling effectiveness distribution on the protected surface in the situation with internal crossflow varies distinctly from that without internal crossflow, which is tightly dependent on the film-hole shape, blowing ratio and crossflow-to-coolant jet velocity ratio. For example, at a blowing ratio of $B r=1.0$, as seen in Figure 14, the presence of internal crossflow with $V r=1.0$ seems have a weaker influence on the adiabatic film cooling effectiveness distributions. Under $V r=2.0$, the local high- $\eta_{\text {ad }}$ zone near the film-hole outlet is reduced, either for the cylindrical or fan-shaped hole. At high blowing ratios, the effect of internal crossflow on the adiabatic film cooling effectiveness distribution behaves more obviously. Under $V r=2.0$, the local high- $\eta_{\text {ad }}$ zone behind the film-hole outlet is reduced and its location is moved toward the $-y$ side for the cylindrical hole. However, far from the film-hole outlet, as the coolant jet issuing from the cylindrical hole is pushed toward $+y$ side, the $\eta_{\text {ad }}$ contours are deflected toward $+y$ side in accordance to the internal flow direction, as seen in Figure 15(c-1) and Figure 16(c-1). For the fan-shaped hole, the un-symmetrically branched $\eta_{\text {ad }}$ contours are induced under a high crossflow-to-coolant jet velocity ratio, as seen in Figure 15(c-2) and Figure 16(c-2). The long strip is deflected toward $-y$ side and the short strip is deflected toward $+y$ side respectively, reflecting that the internal flow effect shows a contrary behavior on the far downstream flow of coolant jet issuing from the fan-shaped hole in comparison with the cylindrical hole (similar to that demonstrated by Saumweber, and Schulz, 2008).

Figure 17 presents the internal crossflow effect on laterally-averaged adiabatic film cooling effectiveness under three typical blowing ratios. It is seen from Figure 17(a) that the internal crossflow has little influence on laterally-averaged film cooling effectiveness distributions for both film cooling holes under a relative low blowing ratio of $B r=1.0$. Under a moderate blowing ratio of $B r=2.0$, as seen in Figure 17(b), the laterally-averaged film cooling 
effectiveness distributions for fan-shaped hole is also nearly unaffected by the presence of internal flow. However, for cylindrical hole, the effect of internal crossflow appears obviously with a complicated influencing role. In comparison with the situation without internal crossflow, a moderate crossflow-to-coolant jet velocity ratio $(V r=1.0)$ increases the laterally-averaged film cooling effectiveness between $s / d=5$ and $s / d=15$. But a high crossflow-to-coolant jet velocity ratio $(V r=2.0)$ decreases the laterally-averaged film cooling effectiveness significantly. Under a high blowing ratio of $B r=3.0$, as seen in Figure 17(c), the laterally-averaged film cooling effectiveness distribution is clearly affected by the internal crossflow effect. In general, a moderate crossflow-to-coolant jet velocity ratio $(V r=1.0)$ is found to play a positive role on film cooling improvement but a high crossflow-to-coolant jet velocity ratio $(V r=2.0)$ is confirmed to reduce the laterally-averaged film cooling effectiveness.

The current results could be partly validated in comparison to the previous researches on the internal crossflow effect over a flat-surface. For instances, under a moderate crossflow-to-coolant jet velocity ratio, the internal crossflow effect was found to improve the film cooling effectiveness for the cylindrical hole but the situation was contrary for the fan-shaped hole generally (e.g. Gritsch et al., 2003; Saumweber and Schulz, 2008; Peng and Jiang, 2012). The above tendencies are also demonstrated vaguely in the current study. As the film cooling holes are located on the suction side of a turbine blade, the acceleration of primary flow presents a strong role on the mutual interaction between coolant jet and mainstream, the effect of internal crossflow on the laterally-averaged film cooling effectiveness distribution is less profound than that on a flat surface case, especially for the fan-shaped hole.

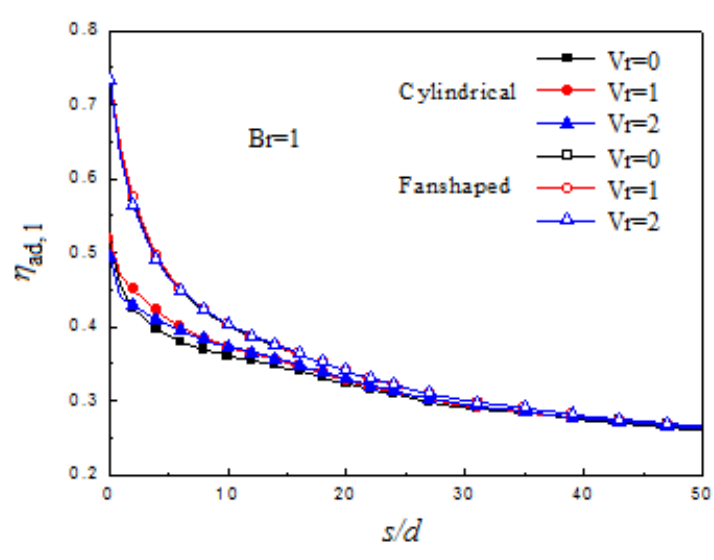

(a) $\mathrm{Br}=1.0$

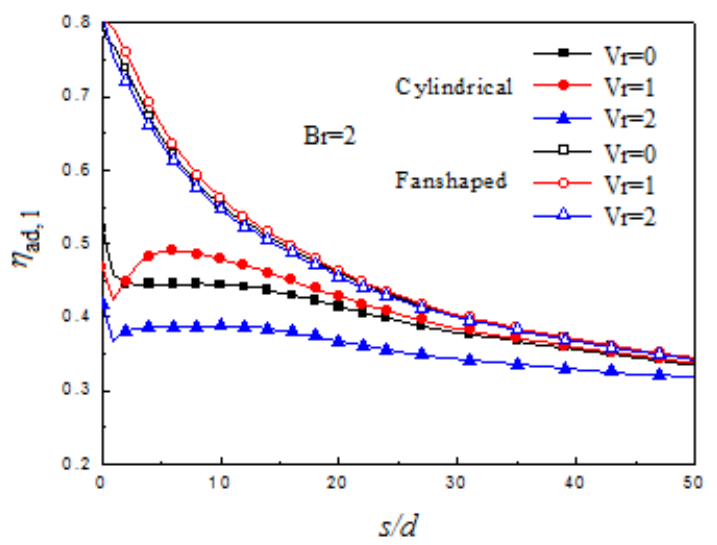

(b) $\mathrm{Br}=2.0$

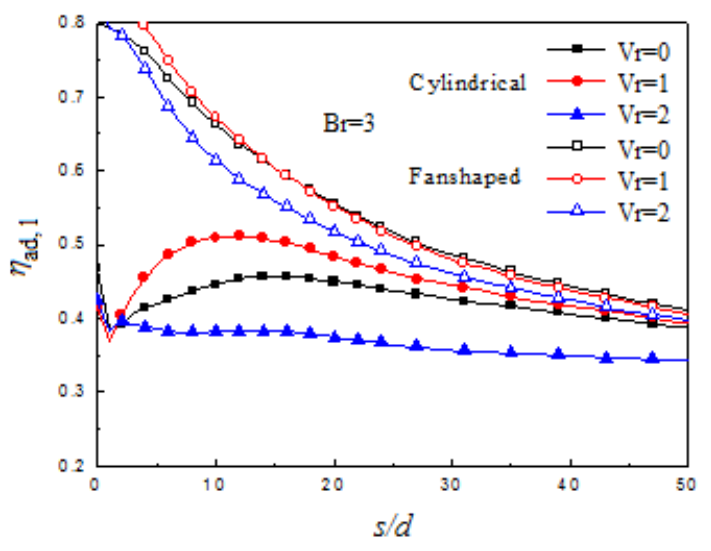

(c) $\mathrm{Br}=3.0$

Fig.17 Effect of internal crossflow on the lateral average adiabatic film cooling effectiveness.

\section{Conclusions}

A series of numerical simulations are performed to study the internal crossflow effect on film cooling performances of single row film-holes on the turbine blade suction surface, under a representative film-cooled engine-simulated condition. The cylindrical and fan-shaped holes are considered, both having the same length-to-diameter of 3 . In the 
current simulations, the blowing ratio $(B r)$ is selected as 1,2 and 3 respectively. The velocity ratio of the internal crossflow to ejection jet $(V r)$ is selected as 0,1 and 2, respectively. From the current investigation, the main conclusions are obtained.

(1) The combinition of internal crossflow effect and entrance jetting effect make the coolant flow inside film cooling hole more complicated, featured as a helical flow. The coolant flow after ejection from film cooling hole is pushed toward one side in accordance to the internal flow direction. The internal crossflow effect on mutual interaction between ejection jet and primary flow downstream the film cooling hole is relatively weaker for fan-shaped hole in compared to cylindrical hole.

(2) The presence of internal crossflow increases the pressure drop across the hole, resulting in the reduction of discharge coefficient of film cooling hole. In general, the velocity ratio of $V r=1.0$ has a little influence on film-hole discharge coefficient. However, under a high velocity ratio of $V r=2.0$, approximately 15\% 20\% reduction of discharge coefficient is produced for the cylindrical hole, and 20\% 27\% reduction for the fan-shaped hole.

(3) The internal crossflow effect on adiabatic film cooling effectiveness distribution is tightly dependent on the film-hole shape, blowing ratio and crossflow-to-coolant jet velocity ratio. In the viewing of laterally-averaged adiabatic film cooling effectiveness, the impact of internal crossflow effect is more profound for the cylindrical hole. In general, a moderate velocity ratio $(V r=1.0)$ plays a positive role on film cooling improvement but a high velocity ratio $(V r=2.0)$ is confirmed to reduce the laterally-averaged film cooling effectiveness.

\section{Acknowledgments}

The authors gratefully acknowledge the financial supports for this project from the National Natural Science Foundation of China (grant No: U1508212).

\section{References}

Agata, Y., Takahashi, T., Sakai, E. and Nishino, K., Effects of orientation of internal turbulence promoting ribs on flow characteristics for film cooling, Journal of Thermal Science and Technology, Vol.8, No.1 (2013a), pp. 15-27.

Agata, Y., Takahashi, T., Sakai, E. and Nishino, K., Numerical simulation of heat transfer coefficient and film-cooling performance influenced by the orientation of internal turbulence promoting ribs, Journal of Thermal Science and Technology, Vol.8, No.3 (2013b), pp. 488-503.

Alameldin, A., El-Gabry, L.A., Fridh, J. and Saha, A., CFD analysis of suction and pressure side film cooling influence on vane aero performance in a transonic annular cascade, ASME Paper GT2014-26617 (2014).

Arts, T., De Rouvroit, M.L. and Rutherford, A.W., Aero-thermal investigation of a highly loaded transonic linear turbine guide vane cascade, VKI Technical Note 174 (1990).

Bell, C.M., Hamakawa, H. and Ligrani, P.M., Film cooling from shaped holes, ASME Journal of Heat Transfer, Vol.122, No.2 (2000), pp. 224 -232.

Bunker, R.S., A review of turbine shaped film cooling technology, ASME Journal of Heat Transfer, Vol.127, No.4 (2005), pp. 441-453.

Bunker, R.S., Gas turbine heat transfer: ten remaining hot gas path challenges, ASME Journal of Turbomachinery, Vol.129, No.2 (2007), pp. 193-210.

Dai, P. and Lin, F., Numerical study on film cooling effectiveness from shaped and crescent holes, Heat and Mass Transfer, Vol.47, No.2 (2011), pp. 147-154.

Ely, M.J. and Jubran, B.J., A numerical evaluation on the effect of sister holes on film cooling effectiveness and the surrounding flow filed, Heat Mass Transfer, Vol.45, No.11 (2009), pp. 1435-1446.

Ethridge, M.I., Cutbirth, J.M. and Bogard, D.G., Scaling of performance for varying density ratio coolants on an airfoil with strong curvature and pressure gradient effects, ASME Journal of Turbomachinery, Vol.123, No.2 (2001), pp. 231-237.

Fawcett, R.J., Wheeler, A.P.S., He, L. and Taylor, R., Experimental investigation into the impact of crossflow on the coherent unsteadiness within film cooling flows, International Journal of Heat and Fluid Flow, Vol.40, No.1 (2013), pp. 32-42.

Gao, Z.H., Narzary, D.P. and Han, J.C., Film cooling on a gas turbine blade pressure side or suction side with axial 
shaped holes, International Journal of Heat and Mass Transfer, Vol.51, No.9-10 (2008), pp. 2139-2152.

Gao, Z.H., Narzary, D.P. and Han, J.C., Film-cooling on a gas turbine blade pressure side or suction side with compound angle shaped holes, ASME Journal of Turbomachinery, Vol.13, No.1 (2009), pp. 011019, 11 pages.

Goldstein, R.J., Eckert, E.R.G. and Burggraf, F., Effects of hole geometry and density on three-dimensional film cooling, International Journal of Heat and Mass Transfer, Vol.17, No.3-4 (1974), pp. 595-607.

Gritsch, M., Schulz, A. and Wittig, S., Adiabatic wall effectiveness measurements of film-cooling holes with expanded exits, ASME Journal of Turbomachinery, Vol.120, Issue 3 (1998a), pp. 549-556.

Gritsch, M., Schulz, A. and Wittig, S., Discharge coefficient measurements of film-cooling holes with expanded exits, ASME Journal of Turbomachinery, Vol.120, No.4 (1998b), pp. 557-563.

Gritsch, M., Schulz, A. and Wittig, S., Effect of internal coolant crossflow on the effectiveness of shaped film-cooling holes, ASME Journal of Turbomachinery, Vol.125, No.3 (2003), pp. 547-554.

Harrison, K. and Bogard, D., Comparison of RANS turbulence models for prediction of film cooling performance, ASME Paper GT2008-50366 (2008).

Haven, B.A., Yamagata, D.K., Kurosaka, M., Yamawaki, S. and Maya, T., Anti kidney pair of vortices in shaped holes and their influence on film cooling effectiveness, ASME Paper 97-GT-45 (1997).

Heidmann, J.D., Rigby, D.L. and Ameri, A.A., A three-dimensional coupled internal/external simulation of a film-cooled turbine vane, NASA TM-1999-209078 (1999).

Heidmann, J.D. and Ekkad, S., A novel antivortex turbine film-cooling hole concept, ASME Journal of Turbomachinery, Vol.130, No.3 (2008), pp. 31020.

Hylton, L.D., Mihelc, M.S., Turner, E.R., Nealy, D.A. and York, R.E., Analytical and experimental evaluation of the heat transfer distribution over the surface of turbine vanes, NASA CR-168015 (1983).

Kim, J.H. and Kim, K.Y., Surrogate-based optimization of a cratered cylindrical hole to enhance film-cooling effectiveness, Journal of Thermal Science and Technology, Vol.11, No.2 (2016), pp. 16-00208, 14 pages.

Kohli, A. and Thole, K.A., Entrance effects on diffused film-cooling holes, ASME Paper 98-GT-402 (1998).

Lee, K.D. and Kim, K.Y., Shape optimization of a fan-shaped hole to enhance film-cooling effectiveness, International Journal of Heat and Mass Transfer, Vol.53, No.15-16 (2010), pp. 2996-3005.

Lee, K.D. and Kim, K.Y., Surrogate based optimization of a laidback fan-shaped hole for film-cooling, International Journal of Heat and Fluid Flow, Vol.32, No.1 (2011), pp. 226-238.

Leylek, J.H. and Zerkle, R.D., Discrete-jet film cooling: a comparison of computational results with experiments, ASME Journal of Turbomachinery, Vol.113, No.3 (1994), pp. 358-368

Li, W.H., Li, X.Y., Ren, J. and Jiang, H.D., Large eddy simulation of compound angle hole film cooling with hole length-to-diameter ratio and internal crossflow orientation effects, International Journal of Thermal Science, Vol.121, No.3-4 (2017), pp. 410-423.

Liu, C.L., Zhu, H.R., Bai, J.T. and Xu, D.C., Film cooling performance of converging slot-hole rows on a gas turbine blade, International Journal of Heat and Mass Transfer, Vol.53, No.23-24 (2010), pp. 5232-5241.

McClintic, J.W., Klavetter, S.R., Winka, J.R., Anderson, J.B., Bogard, D. G., Dees, J.E., Laskowski, G.M. and Briggs, R., The effect of internal crossflow on the adiabatic effectiveness of compound angle film cooling holes, ASME Journal of Turbomachinery, Vol.137, No.7 (2015), pp. 071006, 10 pages.

McClintic, J.W., Anderson, J.B., Bogard, D.G., Dyson, T.E. and Webster, Z.D., Effect of internal crossflow velocity on film cooling effectiveness-part I: axial shaped holes, ASME Journal of Turbomachinery, Vol.140, No.1 (2018), pp. 011003, 10 pages.

McClintic, J.W., Anderson, J.B., Bogard, D.G., Dyson, T.E. and Webster, Z.D., Effect of internal crossflow velocity on film cooling effectiveness-part II: compound angle shaped holes, ASME Journal of Turbomachinery, Vol.140, No.1 (2018), pp. 011004, 10 pages.

Okita, Y. and Nishiura, M., Film effectiveness performance of an arrowhead-shaped film-cooling hole geometry, ASME Journal of Turbomachinery, Vol.129, No.2 (2007), pp. 331-339.

Peng, W. and Jiang, P.X., Experimental and numerical study of film cooling with internal coolant cross-flow effects, Experiments in Heat Transfer, Vol.25, Issue 4 (2012), pp. 282-300.

Qin, Y.M., Liu, X.Y., Ren, J. and Jiang, H.D., Effects of compound angle on film cooling effectiveness with different streamwise pressure gradient and convex curvature, International Journal of Heat and Mass Transfer, Vol.86, No.5-6 (2015), pp. 482-491. 
Ramesh, S., Ramirez, D.G., Ekkad, S.V. and Alvin, M.A., Analysis of film cooling performance of advanced tripod hole geometries with and without manufacturing features, International Journal of Heat and Mass Transfer, Vol.94, No.1 (2016), pp. 9-19.

Saumweber, C., Schulz, A. and Wittig, S., Free-stream turbulence effects on film cooling with shaped holes, ASME Journal of Turbomachinery, Vol.125, No.1 (2003), pp. 65-73.

Saumweber, C. and Schulz, A., Comparison of the cooling performance of cylindrical and fan-shaped cooling holes with special emphasis on the effect of internal coolant crossflow, ASME Paper GT2008-51036 (2008).

Silieti, M., Divo, E. and Kassab, A.J., Numerical investigation of adiabatic and conjugate film cooling effectiveness on a single cylindrical film-cooling hole, ASME Paper IMECE2004-62196 (2004).

Silieti, M., Kassab, A.J. and Divo, E., Film cooling effectiveness: comparison of adiabatic and conjugate heat transfer CFD models, International Journal of Thermal Science, Vol.48, No.12 (2009), pp. 2237-2248.

Sundaram, N. and Thole, K.A., Film-cooling flowfields with trenched holes on an endwall, ASME Journal of Turbomachinery, Vol.131, No.4 (2009), pp. 041007.

Thole, K., Gritsch, M., Schulz, A. and Wittig, A.S., Flowfield measurements for film-cooling holes with expanded exits, ASME Journal of Turbomachinery, Vol.120, No.2 (1998), pp. 327-336.

Wang, C.H., Zhang, J.Z. and Zhou, J.H., Optimization of a fan-shaped hole to improve film cooling performance by RBF neural network and genetic algorithm, Aerospace Science and Technology, Vol.58, No.1 (2016), pp. $18-25$.

Wang, Z., Liu, J.J. and Zhang, C., Multi-field coupling analysis on the film-cooling of a turbine guide vane, ASME Paper GT2013-94256 (2013).

Wilfert, G. and Wolff, S., Influence of internal flow on film cooling effectiveness, ASME Journal of Turbomachinery, Vol.122, No.2 (2000), pp. 327-333.

Yang, C.F. and Zhang, J.Z., Experimental investigation on film cooling characteristics from a row of holes with ridge-shaped tabs, Experimental Thermal and Fluid Science, Vol.37, No.1 (2012), pp. 113-120.

Yao, Y., Zhang, J.Z. and Wen, G., Numerical investigation on film cooling effectiveness of stator blade with different angles, Journal of Aerospace Power, Vol.24, No.3 (2009), pp. 507-512.

Yao, Y., Zhang, J.Z. and Tan, X.M., Numerical study of film cooling from converging slot-hole on a gas turbine blade suction side, International Communications in Heat and Mass Transfer, Vol.52, No.1 (2014), pp. 61-72.

Zhu, X.D., Zhang, J.Z., Tan X.M. and Shan, Y., Effect of rotation on film cooling with a single row of shaped holes on blade pressure side, Journal of Thermal Science and Technology, Vol.12, No.2 (2017), pp. 17-00174, 16 pages. 